emerged from the analysis were clearly different: 43 and $35 \mathrm{ppb}$ for the MINO and Logan devices, respectively.

The methodology used in the two devices is different but this is unlikely to explain the differences reported in this study. Indeed, no difference was detected when samples of known NO concentrations ranging $5-100 \mathrm{ppb}$ and ambient air were analysed with both devices ( $\mathrm{p}=0.18$ by paired $\mathrm{t}$-test). Therefore, differences in expiratory manoeuvres were considered. A micro-spirometer connected to the NIOX MINO showed that the expiratory flow achieved, when patients do expire according to manufacturer's recommendations, is identical to that selected on the chemoluminescence analyser (i.e. $50 \mathrm{~mL} \cdot \mathrm{s}^{-1}$ ). In contrast, the mouth pressures generated during the expiratory manoeuvre, when using the two devices, are notably different; $5 \mathrm{cmH}_{2} \mathrm{O} \quad(0.5 \mathrm{kPa})$ is strictly imposed by our chemoluminescence analyser while a range of pressures between 10 and $20 \mathrm{cmH}_{2} \mathrm{O}(0.98$ to $1.96 \mathrm{kPa})$ is allowed with the MINO device. KONDO et al. [10] showed previously that increased expiratory pressures result in increased FeNO levels determined at a flow rate of $50 \mathrm{~mL} \cdot \mathrm{s}^{-1}$ with a chemoluminescence analyser. In order to test this hypothesis, we measured FeNO in 18 subjects (nine control subjects and nine asthma patients) with the chemoluminescence analyser, before and after a change in the circuit resistance that resulted in the generation of a $15 \mathrm{cmH}_{2} \mathrm{O}(1.5 \mathrm{kPa})$ expiratory pressure during the procedure; a $24.6 \pm 17.4 \%$ increase of FeNO levels occurred when the expiratory pressure increased from 5 to $15 \mathrm{cmH}_{2} \mathrm{O}$ (0.5 to $1.5 \mathrm{kPa}$; $\mathrm{p}<0.001$ by paired t-test). Differences in expiratory pressure, therefore, explain a significant part of the difference we observed in FeNO levels measured with the two devices, the remaining part being in agreement with that found in the previously mentioned studies [7-9].

In conclusion, exhaled nitric oxide fraction measured by the handheld device (NIOX MINO) is strongly correlated with, but consistently higher than, exhaled nitric oxide fraction measured by a chemoluminescence analyser that imposes a lower exhalation pressure. This suggests that monitoring exhalation pressure might be important when repeating and comparing exhaled nitric oxide fraction measurements in asthma patients.

A. Michils*, R. Peché ${ }^{\#}$, S. Baldassarre*, Z. Mourid* and A. Van Muylem*

${ }^{*}$ Chest Dept, CUB Erasme, Brussels, and ${ }^{\#}$ Chest Dept, CHU André Vésale, Montigny-le-Tilleul, Belgium.

\section{STATEMENT OF INTEREST}

A statement of interest for this study can be found at www.erj.ersjournals.com/misc/statements.shtml

\section{ACKNOWLEDGEMENTS}

The authors would like to thank D. Young (Young and Associates, London, UK) for assistance.

\section{REFERENCES}

1 Alving K, Weitzberg E, Lundberg JM. Increased amount of nitric oxide in exhaled air of asthmatics. Eur Respir J 1993; 6: 1368-1370.

2 Kharitonov SA, Yates D, Robbins RA, Logan-Sinclair R, Shinebourne EA, Barnes PJ. Increased nitric oxide in exhaled air of asthmatic patients. Lancet 1994; 343: 133-135.

3 Michils A, Baldassarre S, Van Muylem A. Exhaled nitric oxide and asthma control: a longitudinal study in unselected patients. Eur Respir J 2008; 31; 539-549.

4 Smith AD, Cowan JO, Brassett KP, Herbison GP, Taylor DR. Use of exhaled nitric oxide measurements to guide treatment in chronic asthma. N Engl J Med 2005; 352: 2163-2173.

5 Shaw DE, Berry MA, Thomas M, et al. The use of exhaled nitric oxide to guide asthma management: a randomized controlled trial. Am J Respir Crit Care Med 2007; 176: 231-237.

6 Hemmingsson T, Linnarsson D, Gambert R. Novel handheld device for exhaled nitric oxide-analysis in research and clinical applications. J Clin Monit Comput 2004; 18: 379-387.

7 Alving K, Janson C, Nordvall L. Performance of a new hand-held device for exhaled nitric oxide measurement in adults and children. Respir Res 2006; 7: 67.

8 Vahlkvist S, Sinding M, Skamstrup K, Bisgaard H. Daily home measurements of exhaled nitric oxide in asthmatic children during natural birch pollen exposure. J Allergy Clin Immunol 2006; 117: 1272-1276.

9 Menzies D, Nair A, Lipworth BJ. Portable exhaled nitric oxide measurement: comparison with the "gold standard" technique. Chest 2007; 131: 410-414.

10 Kondo R, Haniuda M, Yamanda $\mathrm{T}$, et al. Effects of expiratory pressure on nitric oxide in exhaled breath. Is exhaled nitric oxide really unaffected by pressure? Respir Physiol Neurobiol 2003; 139: 33-40.

DOI: 10.1183/09031936.00025308

\title{
Tacrolimus for antisynthetase syndrome with interstitial lung disease?
}

\section{To the Editors:}

We read with great interest the recent case study by GUGLIELMI et al. [1]. They described the clinical course of a 52-yr-old male admitted to hospital for life-threatening acute respiratory distress syndrome (ARDS) and diagnosed with anti-Jo-1 antibody positive polymyositis (antisynthetase syndrome). Improvement and recovery were mainly attributed to institution of immunomodulatory therapy with tacrolimus.

Polymyositis patients with anti-Jo-1 antibodies are generally responsive to corticosteroids [2]. The patient's condition 
improved when he was given high-dose corticosteroids. He was successfully weaned from the ventilator on day 6 after intubation (which is very good for ARDS). Given that steroids are not greatly beneficial in the treatment of ARDS [3], it is likely that the improvement of the respiratory symptoms in this patient also resulted from the prompt suppression of the inflammatory systemic response by corticosteroids. This, together with appropriate mechanical ventilation, was probably the main reason for a successful outcome. Tacrolimus may have had little or no role in the patient's recovery as it is slowacting and unlikely to have been playing a significant role for several weeks.

In severe interstitial lung disease associated with polymyositis/dermatomyositis that is refractory to corticosteroids, cyclophosphamide has been the treatment of choice in many centres. Tacrolimus has not been widely investigated, it is overly expensive and important adverse events (more nephrotoxicity and neurotoxicity compared with ciclosporin) are common. However, tacrolimus could be reserved for those refractory cases who respond poorly to standard combination regimen.

Finally, could any of the clinical situations be explained by drug side-effects, such as the pneumonitis and rhabdomyolysis that can occur with levofloxacin. Further details of the patient history would also be helpful. Has the pulmonary disease and myositis remained in remission and what therapy is currently being used? We would also encourage the diagnosis of myositis using electromyography and a muscle biopsy.

\section{R. Polosa* and C.J. Edwards"}

*Dipartimento di Medicina Interna, University of Catania, Catania, Italy. "Dept of Rheumatology, Southampton General Hospital, Southampton, UK.

\section{STATEMENT OF INTEREST}

None declared.

\section{REFERENCES}

1 Guglielmi S, Merz TM, Gugger M, Suter C, Nicod LP. Acute respiratory distress syndrome secondary to antisynthetase syndrome is reversible with tacrolimus. Eur Respir J 2008; 31: 213-217.

2 Tillie-Leblond I, Wislez M, Valeyre D, et al. Interstitial lung disease and anti-Jo-1 antibodies: difference between acute and gradual onset. Thorax 2008; 63: 53-59.

3 Calfee CS, Matthay MA. Nonventilatory treatments for acute lung injury and ARDS. Chest 2007; 131: 913-920.

DOI: $10.1183 / 09031936.00029708$

\section{From the authors:}

We thank our colleagues for their letter, providing the opportunity to underline the interest in the relevant case study [1].

Until recently, it was not well recognised that interstitial lung disease in polymyositis patients with anti-Jo-1 can present an acute onset with a severe outcome, as recently reported [2, 3].
Acute respiratory distress syndromes respond to a physiological definition, which does not always present in connection with diffuse alveolar damage but can be related to other processes. In our case report, we show an acute respiratory distress syndrome (ARDS) due to a nonspecific interstitial pneumonitis (NSIP), proven by an open lung biopsy. If an ARDS is properly diagnosed by such specific examinations, a more specific therapy may be applied. In our case, the presence of anti-Jo-1 antibodies with a predominant CD8 cellular NSIP and myositis allowed a precise diagnosis.

As shown in our study, this entity is corticosteroid sensitive but such treatment is often insufficient and makes an additional therapy with immunosuppressors necessary [2]. Cyclophosphamide is still frequently recommended, despite its partial efficiency and high toxicity limiting its use beyond 6-12 months. Our case report underlines again the usefulness of calcineurin inhibitors in this T-cell-mediated disease, which has also been demonstrated previously [3,4]. The toxicity of these drugs, in particular of tacrolimus, is limited if drug monitoring is performed as it is in transplantation [5], currently allowing rather well-tolerated treatments for $>10$ yrs. The rapid improvement of gas exchanges and myositis should allow challenge of the concept that calcineurin inhibitors do not act quickly in settings where the cellular NSIP has not yet been followed by an irreversible lung fibrosis. A long-term improvement has previously been described in 13 patients with severe interstitial diseases [3], who did not respond to more classical immunosuppressors. In these cases, early treatment with tacrolimus is suggested before lung fibrosis is established and we can propose monitoring of the blood while levels of the drug are between 5 and $10 \mathrm{ng} \cdot \mathrm{mL}^{-1}$, in order to optimise the long-term incidence of side effects [5].

In our case and that reported by WILKES et al. [3], low dose steroids and tacrolimus were applied without using other immunosuppressive drugs in order to avoid opportunistic infection. According to WILKES et al. [3], patients received this treatment for an average duration of 51 months. Our patient returned abroad and follow-up was lost after 8 months of successful treatment. In our clinic, such good and long-term follow-up has been experienced in further cases but has not yet been published.

\section{L.P. Nicod}

Dept of Internal Medicine, Hôpital Cantonal Universitaire, Geneva, Switzerland.

\section{STATEMENT OF INTEREST}

None declared.

\section{REFERENCES}

1 Guglielmi S, Merz TM, Gugger M, Suter C, Nicod LP. Acute respiratory distress syndrome secondary to antisynthetase syndrome is reversible with tacrolimus. Eur Respir J 2008; 31: 213-217.

2 Tillie-Leblond I, Wislez M, Valeyre D, et al. Interstitial lung disease and anti-Jo-1 antibodies: difference between acute and gradual onset. Thorax 2008; 63: 53-59. 